Disponível em:

http://editora.unoesc.edu.br/index.php/race

Race, Joaçaba, v. 14, n. 3, p. 1005-1034, set./dez. 2015

\title{
INFLUÊNCIA DA IMAGEM E PERCEPÇÃO DE VALOR NA INTENÇÃO DE COMPRA DE CARNE DE FRANGO: UM ESTUDO QUANTITATIVO
}

\author{
Influence of image and perception of value in the intention of \\ purchasing chicken meat: a quantitative study
}

Deonir De Toni

E-mail:deonirdt@terra.com.br

Pós-Doutor em Administração pela Universidade de São Paulo; Doutor em Administração pela Universidade Federal do Rio Grande do Sul; Professor da Universidade de Caxias do Sul. Endereço para contato: Alameda João Dal Sasso, 558, Borgo, 95700-000, Bento Gonçalves, Rio Grande do Sul, Brasil.

Ricardo Antonio Reche E-mail: ricardo.reche@yahoo.com.br Mestre em Administração pela Universidade de Caxias do Sul; Especialista em Gestão Estratégica da Qualidade pela Universidade de Caxias do Sul; Professor da Faculdade de Integração do Ensino Superior do Cone Sul.

Fabiano Larentis

E-mail: flarenti@ucs.br

Doutor em Administração pela Universidade Federal do Rio Grande do Sul; Mestre em Administração (ênfase em Marketing) pela Universidade Federal do Rio Grande do Sul; Professor dos Cursos de Administração e Comércio Internacional da Universidade de Caxias do Sul.

Gabriel Sperandio Milan

E-mail: gsmilan@ucs.br

Doutor em Engenharia de Produção na área de Sistemas de Qualidade pela Universidade Federal do Rio Grande do Sul; pós-doutorando em Administração na área de Marketing pela Universidade Federal do Rio Grande do Sul; Professor e pesquisador da Universidade de Caxias do Sul e do Centro de Ensino Superior Cenecista de Farroupilha. 


\section{Resumo}

O Brasil ocupa, atualmente, posição destacada no cenário mundial como produtor e exportador de carne de frango, gerando empregos e a permanência do homem no campo. Pesquisas demonstram que o consumo da carne de frango, em escala mundial, cresce a taxas maiores que o de outras carnes. Porém, apesar desse cenário, a percepção dos consumidores sobre a carne de frango ainda carece de atenção por parte dos pesquisadores. Qualitativamente, Reche, De Toni e Milan (2010) apontaram os atributos presentes na imagem central dessa carne, bem como as percepções de valor, demonstrando que os consumidores percebem a carne de frango como um produto saudável, de preço acessível, versátil e leve. Visando demonstrar de modo quantitativo quais dimensões da imagem da carne de frango mais contribuem para a intenção de compra, um instrumento composto por 71 questões relativas à imagem do produto, percepções de valor e intenções de compra e distribuídas em blocos foi aplicado a 213 respondentes, evidenciando que as dimensões racionais, funcionais, sensoriais e físicomateriais da imagem são as mais significativas para a intenção de compra do consumidor. Os atributos e dimensões elencados remetem a ações de marketing em variáveis pontuais, relevantes para a intenção de compra do produto.

Palavras-chave: Imagem da carne de Frango. Percepção de valor. Intenção de compra.

\section{Influence of image and perception of value in the intention of purchasing chicken meat: a quantitative study}

\section{Abstract}

Brazil is currently featured on the world context as a producer and exporter of chicken meat, creating jobs and allowing the permanence of men in the contryside. Researches show that consumption of chicken meat, worldwide, grows at higher rates than the other meats. But despite this scenario, consumers' perception about chicken meat still needs attention from researchers. Qualitatively, Reche, De Toni and Milan (2010) identified the attributes present in the central image of this meat and the value perceptions, demonstrating that consumers perceive the chicken meat as a healthy product, affordable, versatile and light. Aiming to demonstrate quantitatively which dimensions of chicken meat image contribute most to the intention of buying, an instrument composed of 71 questions relating to the image of the product, value perceptions and purchase intentions was applied to 213 respondents, showing that the rational, functional, sensory and physical-material dimensions of the image are the most significant to consumers' purchase intention. The attributes and dimensions listed are related to marketing actions, in specific variables, relevant to the intention to buy the product.

Keywords: Poultry meat image. Perception of value. Purchase intention. 


\section{INTRODUÇÃO}

Em se tratando de comportamento do consumidor, é fato que a multiplicidade de variáveis ou atributos presentes em um produto tem grande influência quando do processo decisório de compra. Como consequência, dentro de um contexto atual da presença de várias marcas e pontos de venda para um mesmo tipo de produto, o consumidor acaba por adotar múltiplos critérios quando das etapas de avaliação de alternativas e do ato de compra.

Em relação à carne de frango, Silva e Fabrini Filho (1994) apontam algumas razões que justificam aumentos progressivos no consumo: é uma carne mais saudável, de fácil digestão e menos gordura, é mais barata e apresenta maior conveniência de preparo. Em estudo realizado na Bélgica, por Verbeke e Viaene (1999), por exemplo, os fatores mais relevantes para o consumidor de carne de aves são: segurança, abrangendo os atributos confiança e livres de substâncias prejudiciais à saúde; características específicas, que englobam os atributos sabor, qualidade, "saudabilidade", teor de gordura e isenção de hormônios; e conveniência, agregando os atributos da facilidade de preparo, preço e maciez.

A produção e o consumo da carne de frango no Brasil e no mundo crescem continuamente. Segundo estudo divulgado recentemente pelo USDA/ERS (2015), considerando-se as previsões para o ano 2015 e comparando-se os dados dos últimos dois anos, a produção bovina nos EUA deve cair 1,4\%, a produção de carne suína deve crescer $1,1 \%$, enquanto a de carne de frango deve aumentar em aproximadamente $1,5 \%$, totalizando 87,3 milhões de quilos.

No contexto brasileiro, Gordin (2002) afirma que entre os fatores que mais contribuíram para o aumento do consumo de carne de frango estão o aumento na eficiência de toda a cadeia produtiva, com a subsequente redução de preços, alterações no poder aquisitivo da população e o baixo custo em relação aos seus substitutos. A União Brasileira de Avicultura (Ubabef, 2015), referenciando o consumo da carne de frango no Brasil, mostra valores de consumo per capita de 41,80 kg/ano em 2013, ou seja, um crescimento de 58,4\% em relação ao ano 2000 (29,91 kg/ano).

No que se refere à imagem de um produto, a percepção da qualidade e de valor pelo consumidor constitui-se em fator determinante nas suas opções de compra e escolha. Para Barich e Kotler (1991), o termo imagem, na sua essência, é amplo e representa um conjunto de crenças, atitudes e impressões que uma pessoa ou grupo de pessoas tem sobre um objeto, o qual pode ser uma empresa, uma marca ou um produto. Essas impressões não são necessariamente verdadeiras, mas 
ajudam a constituir imagens sobre o objeto, as quais influenciarão o comportamento do indivíduo em relação a ele. Aliás, Schiffman e Kanuk (2000) salientam que é preciso considerar que a imagem é uma interpretação das informações recebidas, um conjunto de inferências e reações sobre o produto.

Nesse contexto, Reche, De Toni e Milan (2010) realizaram uma pesquisa qualitativa, buscando verificar quais os atributos componentes da imagem da carne de frango, qual a imagem central desse produto e quais as percepções de valor do consumidor sobre esse tipo de carne. Os resultados evidenciaram que o consumidor percebe a carne de frango como um produto saudável, de preço acessível, versátil e leve.

Dessa forma, em continuidade ao estudo de Reche, De Toni e Milan (2010), objetivou-se, com este trabalho, analisar e identificar as dimensões da imagem mais significativas para a intenção de compra de carne de frango. Cabe ressaltar que o artigo se estrutura sobre um referencial teórico, subdividido em comportamento do consumidor e processo de decisão de compra, definição e organização da imagem de produto e percepção de valor sobre a carne de frango. Na sequência, são apresentados o método da pesquisa e as análises dos resultados, subdivididas em caracterização da amostra e estatísticas descritivas, análise fatorial e análise de regressão múltipla. Por fim, apresentam-se as considerações finais atinentes ao estudo.

\section{REFERENCIAL TEÓRICO}

\subsection{COMPORTAMENTO DO CONSUMIDOR E PROCESSO DE DECISÃO DE COMPRA}

Conforme Pinto e Lara (2007), os estudos de comportamento do consumidor derivam de um crescente corpo de conhecimento da ciência comportamental, percebido como útil para as funções de negócios, especialmente o marketing. Dessa forma, segundo os autores, conhecimentos da antropologia, da psicologia cognitiva e outros foram incorporados à administração, auxiliando a compreender o chamado marketing experiencial, ou seja, a sensação de que os produtos e serviços proporcionam aos consumidores experiências sensoriais, afetivas, cognitivas, físicas e sociais.

Blackwell, Miniard e Engel (2005) definem o comportamento do consumidor como aquele que envolve as atividades diretamente presentes na obtenção, consumo e descarte de produtos ou serviços, incluindo o processo de decisão para tal. Segundo Sheth, Mittal e Newman (2001), é preciso entender porque 
os consumidores compram, o que compram e por que respondem ao mercado da maneira que o fazem. Esses autores trazem o comportamento do consumidor como sendo as atividades físicas, mentais e sociais que resultam em decisões variadas, entre as quais pagar, comprar e usar produtos ou serviços, bem como descartá-los.

Ao longo dos anos, estudando o processo de consumo, pesquisadores têm destacado aspectos como motivações internas e influências externas (como pressões sociais e atividades de marketing), conforme indicam Blackwell, Miniard e Engel (2005). De forma geral, esses autores mostram que existem sete etapas básicas envolvidas no processo de decisão do consumidor:

a) reconhecimento de uma necessidade: uma percepção de diferença entre o estado desejado e o atual, suficiente para ativar um processo decisório;

b) procura por informações: essa procura se passa na própria memória (busca interna) ou no ambiente externo;

c) avaliação de alternativa pré-compra: avaliação de opções em termos de benefícios esperados e, a partir disso, escolha da alternativa preferida;

d) compra: aquisição da alternativa preferida ou de um substituto aceitável;

e) consumo: uso da alternativa adquirida;

f) avaliação de alternativa pós-compra: análise do grau de satisfação proporcionado pela experiência de consumo;

g) descarte: disposição do que não foi consumido ou seus remanescentes.

O processo de decisão também recebe influências de variáveis ambientais e de diferenças ou características individuais. As variáveis ambientais são as relacionadas à cultura, classe social, grupo de pessoas, família e situação específica. As diferenças individuais envolvem recursos do consumidor, motivação e envolvimento, conhecimento, atitudes, personalidade, valores e estilo de vida (BLACKWELL; MINIARD; ENGEL, 2005).

Sobre esse processo de decisão, Schiffman e Kanuk (2000) ressaltam que para cada indivíduo a realidade é um fenômeno totalmente pessoal, baseado em necessidades, desejos, valores e experiências pessoais. Assim, o que os consumidores pensam afeta as suas ações, seus hábitos de compra, seus hábitos de lazer e assim 
por diante. Ainda, segundo esses autores, a percepção pode ser definida como o processo pelo qual um indivíduo seleciona, organiza e interpreta estímulos visando a um quadro significativo e coerente do mundo, sendo esses estímulos podem incluir produtos, embalagens, marcas, anúncios e comerciais, normalmente captados pelos receptores sensoriais (olhos, ouvidos, nariz, boca e pele) e ser utilizados no processo de avaliação e uso da maioria dos produtos de consumo.

Solomon (2002) alerta que, quando os consumidores processam informações sobre um produto, não o fazem "no vácuo". Ao contrário, o estímulo de um produto é avaliado em termos de o que as pessoas já sabem sobre ele ou sobre coisas com as quais se assemelham. Assim, torna-se importante compreender como esse conhecimento é representado na estrutura cognitiva do consumidor, ou seja, no conjunto de conhecimentos sobre produtos, isto é, crenças e o modo como elas estão organizadas na mente das pessoas.

Para Mowen e Minor (2003), o conhecimento do consumidor é definido como a quantidade de experiência e informação que uma pessoa tem acerca de determinados produtos ou serviços. À medida que aumenta o conhecimento do consumidor sobre um produto, a pessoa pode pensar nesse produto considerando um número maior de dimensões e fazer distinções mais apuradas entre as marcas. Por exemplo, um consumidor que seja um grande conhecedor de vinhos pode considerar dimensões múltiplas, como a cor, o aroma, a acidez e assim por diante. Já um principiante poderá considerar uma única dimensão (por exemplo, o quanto ele gosta do sabor do vinho).

Paralelamente, Hawkins, Mothersbaugh e Best (2007) ressaltam que os consumidores utilizam dois tipos principais de processos de escolha de produtos: a escolha baseada em atributos e a escolha baseada em atitudes. No caso da escolha baseada em atributos (objeto desta pesquisa), são considerados atributos específicos, o que exige mais esforço e consome mais tempo do que as comparações entre produtos com base em atitudes. Tal processo, segundo os autores, tende a gerar uma decisão próxima da ótima. Por isso da importância em se buscar conhecer quais os atributos mais significativos para a imagem do produto no mercado, principalmente na perspectiva dos consumidores. 


\subsection{DEFINIÇÃO E ORGANIZAÇÃO DA IMAGEM DE PRODUTO}

O termo imagem, amplamente discutido pelos pesquisadores e profissionais de Marketing, pode assumir diferentes significados, dependendo da ótica sob a qual está sendo analisado e de sua origem e formação.

Lindquist (1975) foi um dos primeiros autores a afirmar que a imagem combina um conjunto de fatores tangíveis (funcionais) e intangíveis (cognitivos, simbólicos e emocionais). Posteriormente, Levy (1981) reforçou essa ideia, mostrando que os atributos simbólicos são tão importantes quanto os atributos funcionais e que os produtos apresentam uma imagem de personalidade, assim como as pessoas. Essa personalidade não é determinada somente por características físicas do produto, mas também por um conjunto de outros fatores, como a propaganda, o preço e outras associações psicológicas. Assim, imagem é o que as pessoas pensam e sentem sobre o produto ou marca, sendo condicionada pela natureza do objeto, bem como pela natureza do observador (STERN; ZINKHAN; JAJU, 2001).

Dichter (1985) afirma que imagem é um conceito que pode ser aplicado a vários objetos de estudo e descreve não somente as qualidades destes, mas o total de impressões formadas durante as observações dos indivíduos. Ainda segundo esse autor, uma imagem não está ancorada somente em dados objetivos e análises, mas também sobre a influência da publicidade e da disposição e atitudes do consumidor durante suas observações.

Para Barich e Kotler (1991), o termo imagem representa um conjunto de crenças, atitudes e impressões que uma pessoa ou um grupo de pessoas têm sobre um objeto. Esse objeto pode ser uma empresa, uma marca ou, como, no caso em questão, um produto. Essas impressões não são necessariamente verdadeiras. Mas, de qualquer forma, ajudam a constituir imagens sobre o objeto que influenciarão o comportamento do indivíduo em relação àquele.

Por sua vez, Zaltman (2000) afirma que, em razão da complexidade do comportamento do consumidor, esse fenômeno necessita ser abordado de forma multidisciplinar. Dessa forma, para considerar a imagem como um fenômeno multidimensional e holístico, é preciso aceitar que a imagem seja constituída com informações advindas dos diversos níveis de percepção.

Porém, a grande questão a respeito de uma imagem gira em torno de sua composição, ou seja, quais os tipos de informações que a compõem. De Toni (2009) 
afirma que as informações podem ser de origem racional, sensorial, emocional e simbólica. As informações racionais dizem respeito ao que o indivíduo já conhece sobre o objeto. As informações sensoriais se fundamentam naquilo que ele percebe, por meio dos sentidos, sobre o objeto. O conteúdo emocional se forma a partir de um contato anterior com o objeto e se essa aproximação trouxe uma carga de emoção. Já as informações de cunho simbólico têm origem em analogias que a pessoa pode fazer comparando o objeto com outros. Esses dados vão interagir na formação da ideia do objeto, formando a imagem dele.

Outros autores também abordam os elementos componentes da imagem, incluindo mais tipos de informações. Como elementos simbólicos, os produtos são avaliados pelo que eles representam ou significam para o indivíduo (LEVY, 1981; MARTINEAU, 1958). Já os elementos cognitivos ou racionais são construções mentais sobre o objeto, pelos quais o indivíduo avalia a imagem do produto como uma impressão e um conjunto de atitudes e percepções sobre o objeto (DICHTER, 1985). Por outro lado, os elementos emocionais revelam o conjunto de sentimentos (prazer, dor, alegria, medo, etc.) que o indivíduo carrega em relação ao produto (LEDOUX, 1998).

Para De Toni, Milan e Schuler (2009), o nivel de percepção afetiva em relação ao objeto (no caso um produto) contém sentimentos mais elaborados, que percebem o valor do objeto para a socialização e a interação afetiva do indivíduo com o seu ambiente, conduzindo a um reconhecimento ou negação de sua utilidade, respeito e gratidão por sua existência e valorização de suas características.

Os atributos sensoriais se referem às impressões visuais, auditivas, olfativas, palatais e táteis que os objetos deixam nas pessoas (cor, peso, textura, barulho, odores, temperatura, etc.). São impressões importantes para a formação da imagem de um objeto porque se referem à experiência mais concreta e direta que o indivíduo tem com ele (STERN; ZINKHAN; JAJU, 2001).

Os atributos visionários correspondem à dimensão do produto esperado. Não é aquilo que o consumidor vê, testa e tem, mas aquilo com que ele sonha a respeito do produto. Esses atributos constituem uma dimensão importante da imagem do produto para as organizações que desejam introduzir evolução à sua oferta ao mercado, acompanhando as suas tendências (KOTLER; KELLER, 2012).

Além disso, na visão de Schuler, De Toni e Milan (2009), na condição de elementos físicos e materiais, estão inseridas todas as realidades alcançadas pelos sentidos e sensações humanas, incorporando hábitos, costumes e crenças acerca da 
saúde, higiene e vestimenta ao ambiente físico e suas variações, à forma de satisfação de necessidades fisiológicas, aos critérios econômicos e aos modos de vida.

Por fim, Barich e Kotler (1991) trazem o debate sobre a questão do valor na relação com a imagem do produto. Segundo esses autores, uma boa imagem consiste em quanto os clientes e outros públicos percebem valor no que está sendo oferecido, em comparação com outros objetos. Valores altos podem ser originários de bons produtos ou serviços, bem como de preços adequados, entre outros.

\subsection{O CONSUMO DE CARNE DE FRANGO}

Segundo estudo divulgado recentemente pelo United States Department of Agriculture/Economic Service Research (2015), considerando-se as previsões para o ano 2015 e comparando-se valores dos últimos dois anos, o consumo de carne bovina nos EUA deve cair 1,6\%, enquanto o consumo de carne de frango deve crescer 1,5\%, equiparando-se ao da carne suína, atingindo mais de 85 milhões de quilos.

Acompanhando essa tendência, a União Brasileira de Avicultura (2015), referenciando o consumo no Brasil, destaca valores de consumo per capita de 41,80 $\mathrm{kg} / \mathrm{ano}$ em 2013, ou seja, um crescimento de 58,4\% em relação ao ano 2000 (29,91 $\mathrm{kg} / \mathrm{ano})$.

Silva e Fabrini Filho (1994) apontam as seguintes razões que justificam o aumento no consumo de frango: é uma carne mais saudável, de fácil digestão e menos gordurosa, é mais barata e apresenta maior conveniência de preparo. Kennedy et al. (2004) reforçam essa ideia por meio de pesquisa realizada em quatro países, mostrando importantes aspectos da qualidade da carne apontados por consumidores na sua opção por carne de frango, destacando-se, entre eles, maciez, frescor, "saudabilidade" e nutrição.

Por outro lado, quando se aborda a questão nutricional, autores como Hubert (2000) mostram que a nutrição, na história da humanidade, sempre desempenhou papel maior do que a simples provisão de energia. Ela engloba necessidades fisiológicas, mas também incorpora dimensões simbólicas e imaginárias, aspectos importantes nas relações do homem com os alimentos. Nesse sentido, Spers (2003) afirma que o consumidor quer garantias de que está consumindo um alimento saudável, sem riscos à saúde.

Em acréscimo, Arenales (2003) ressalta que o uso de aditivos na produção de aves confinadas e as dúvidas sobre seus resíduos na carne são preocupações 
dos consumidores. Porém, para Bolis (2002), a população nem sempre possui um entendimento completo sobre o assunto, o que a leva a ter crenças e receios infundados.

É oportuno destacar que Francisco (2004) compartilha essa ideia, com base na afirmação de que a rastreabilidade dos processos produtivos, a rotulagem e alguns dispositivos de segurança são implementados para diminuir as preocupações do consumidor. Porém, para a autora, as normas e realizações são de difícil comunicação e têm o risco de serem percebidas pelo consumidor como insuficientes e sem sentido. Ainda segundo a autora, pode-se afirmar que o uso de hormônios como promotores de crescimento para animais destinados à alimentação humana é um mito, na medida em que a legislação brasileira proíbe o uso desse tipo de precedente; o efeito desse tipo de tratamento é muito demorado (mínimo 30 dias, tornando-se inviável para a carne de frango, oriunda de abate de aves com aproximadamente 40 dias), além de o custo ser elevado. O manejo dos animais e os cuidados com a sanidade e o tipo de alimentação que recebem são os responsáveis pela obtenção desse tipo de carne em curtos intervalos de tempo.

Dessa forma, o questionamento sobre a origem das informações acerca da presença de hormônios na carne de frango se faz importante. Francisco (2004), por meio de pesquisas com consumidores, mostrou que essa crença parte dos meios de comunicação (43\%), jornais (34\%) e revistas (25\%), amigos e parentes $(23 \%)$, médicos e profissionais da saúde (12\%), bem como internet e opinião própria (20\%). Entretanto, tais consumidores não sabem relatar a origem da fonte, o que remete ao fato de que esse atributo merece ser objeto de atenção por parte dos profissionais da cadeia avícola e de Marketing.

\subsection{IMAGEM E PERCEPÇÃO DE VALOR DA CARNE DE FRANGO}

Em trabalho realizado por Reche, De Toni e Milan (2010), de natureza qualitativo-exploratória, a imagem da carne de frango foi identificada a partir do levantamento de atributos concernentes ao produto, segundo a visão de consumidores e varejistas. Em uma segunda etapa, esses atributos foram organizados e classificados conforme os pressupostos do Método de Configuração da Imagem (MCI), já validado por De Toni (2005), o que permitiu classificá-los como pertencentes às Imagens Central e Periférica. 
A pesquisa demonstrou que a imagem central era composta por oito atributos principais, elencados pela ordem em saudável, melhor preço, família (reuniões, infância), sabor, versátil, carne leve, aparência e hormônios (presença, malefícios à saúde). Esses atributos, segundo De Toni e Schuler (2007), são mais estáveis e resistentes à mudança e contribuem para atribuir significado ao produto.

O estudo despertou atenção também para o fato de os consumidores ressaltarem em primeiro lugar a questão da saudabilidade da carne de frango, ao mesmo tempo que, contraditoriamente, salientarem a crença em atributos negativos, como a presença de hormônios. Isso revela certa confusão do consumidor em termos da percepção de valor do produto pesquisado (relação benefícios versus sacrifícios).

Quanto ao entendimento sobre como estava configurada a percepção de valor para o produto carne de frango, em termos de benefícios e sacrifícios, o trabalho dos autores mostrou que havia uma interessante e, de certa forma, equilibrada distribuição percentual para os consumidores de carne de frango entre os fatores, marcadamente apontada pelos $42 \%$ de sacrifícios e $58 \%$ de benefícios.

\section{MÉTODO DE PESQUISA}

Este estudo é caracterizado como de natureza quantitativa, de nível descritivo, tendo sido utilizada uma survey como estratégia de pesquisa. O questionário foi elaborado com base em revisões bibliográficas acerca dos temas ligados à imagem de produtos, percepção de valor e intenções de compra, assim como nos resultados provenientes do estudo de Reche, De Toni e Milan (2010). O instrumento, composto por 71 questões relativas à imagem do produto, percepções de valor e intenções de compra distribuídas em blocos, bem como por oito questões relativas ao perfil dos respondentes, foi enviado a dois especialistas da área de Marketing, para a validação do instrumento. Utilizou-se uma escala de concordância de cinco pontos, sendo 1 atribuído a "discordo totalmente" e 5 a "concordo totalmente".

$\mathrm{Na}$ sequência, o questionário foi aplicado a 17 respondentes, estudantes universitários de um município da Serra Gaúcha, em um pré-teste, sendo constatada sua adequação ao proposto. Considerando-se uma amostragem do tipo não probabilística por conveniência, em seguida, foram aplicados 213 questionários a um público formado por estudantes universitários da Serra Gaúcha, obtendo-se uma taxa de retorno de $100 \%$, facilitada pela presença do entrevistador nos locais de 
aplicação. Salienta-se, também, que o tempo médio utilizado pelos respondentes para o preenchimento dos questionários foi de aproximadamente 11 minutos.

Findo o processo de aplicação dos questionários, iniciou-se o processo de preparação dos dados, por meio da seleção dos questionários aceitáveis (MALHOTRA, 2006). Foi realizada, primeiramente, uma edição dos questionários respondidos, o que, segundo Malhotra (2006), visa identificar não apenas a integridade dos instrumentos coletados, mas também a análise de respostas ilegíveis, incompletas, inconsistentes, ambíguas e insatisfatórias por razões diversas. Ao final dessa fase, foram descartados sete questionários, restando 206 considerados aptos ao estudo (casos válidos).

$\mathrm{Na}$ sequência do processo de preparação dos dados, efetuou-se o que se denomina limpeza dos dados, verificando nos questionários a sua consistência, bem como o tratamento de respostas omitidas (MALHOTRA, 2006). Foram eliminados 11 casos com mais de $10 \%$ de dados omissos (KLINE, 2011), totalizando, dessa forma, ao final do processo de preparação, 195 casos considerados apropriados à sequência de análises estatísticas.

Também foi realizada uma análise dos chamados outliers. Segundo Kline (2011), a presença de outliers pode ser detectada mediante testes multivariados, como o de Mahalanobis (distância $\mathrm{D}^{2}$ ), sendo eliminados casos com significância menor que 0,001 (HAIR JUNIOR et al., 2005). Para o presente trabalho, não foram detectados casos em que houvesse a necessidade da eliminação dos outliers, mediante a utilização do teste supracitado.

Na medida em que análises multivariadas também presumem a normalidade dos dados, foram efetuados testes de assimetria e curtose, sugeridos por Kline (2011). Valores absolutos de assimetria acima de $|3|$ podem ser tomados como extremamente assimétricos, enquanto valores de curtose acima de $|10|$ podem indicar problemas. No estudo, verificou-se a inexistência desse tipo de problema (KLINE, 2011).

Em seguida, a análise dos dados considerados válidos foi realizada mediante o uso do software Statistical Package for Social Sciences (SPSS) 21.0. Além de estatísticas descritivas, efetuaram-se a análise fatorial e a análise de regressão múltipla. 


\section{RESULTADOS E DISCUSSÕES}

\subsection{CARACTERIZAÇÃO DA AMOSTRA}

De modo geral, a faixa etária dos respondentes situou-se abaixo dos 30 anos de idade, havendo também um equilíbrio entre os gêneros masculino e feminino (53,9\% e 46,1\%, respectivamente). Em relação à renda média dos pesquisados, evidenciou-se certa divisão no perfil dos entrevistados, basicamente um grupo sendo formado por pessoas com renda na faixa de até três Salários Mínimos (SM) e outro grupo por pessoas com renda acima de três SM (60,2\% e 39,8\%, respectivamente).

No que diz respeito à frequência de consumo, os entrevistados foram divididos em dois grupos principais: os que costumam consumir carne de frango até duas vezes por semana $(62,3 \%)$, e os que costumam consumir esse produto mais de duas vezes por semana $(37,7 \%)$.

\subsection{ESTATÍSTICAS DESCRITIVAS DOS CONSTRUTOS}

Inicialmente, apresentam-se as Tabelas 1 e 2, demonstrando estatísticas descritivas dos construtos Dimensão Físico-Material e Emocional. Com base na Tabela 1, a média geral da dimensão Físico-Material de imagem da carne de frango ficou em 3,44, com um desvio padrão (DP) médio de 1,13. Salientam-se, também, os valores maiores e menores: 4,04 para a questão referente à observação do prazo de validade do produto no momento da compra e 2,38 para a questão referente à carne de frango ser um produto caro. 
Tabela 1 - Estatísticas descritivas da dimensão físico-material

\begin{tabular}{lcc}
\hline \multicolumn{1}{c}{ Variáveis relativas à dimensão físico-material } & Média & DP \\
\hline $\begin{array}{l}\text { Observo a carne de frango pelo seu prazo de validade no momento da } \\
\text { compra. }\end{array}$ & 4,04 & 1,17 \\
$\begin{array}{l}\text { A carne de frango possui melhor preço que os outros tipos de carne. } \\
\text { Observo as características da embalagem para escolher a carne de }\end{array}$ & 3,97 & 1,03 \\
frango. & 3,88 & 0,99 \\
$\begin{array}{l}\text { A carne de frango que apresenta excesso de água e/ou gelo não repre- } \\
\text { senta nenhum benefício para mim. }\end{array}$ & 3,88 & 1,15 \\
$\begin{array}{l}\text { A carne de frango apresenta excesso de água e/ou gelo. } \\
\text { Pagaria mais por uma carne de frango com maiores garantias de sauda- }\end{array}$ & 3,84 & 1,13 \\
$\begin{array}{l}\text { bilidade (benefícios à saúde). } \\
\text { Pagaria mais por uma carne de frango que apresentasse, visualmente, } \\
\text { menor quantidade de água e/ou gelo. }\end{array}$ & 3,67 & 1,21 \\
$\begin{array}{l}\text { O fato de a carne de frango ser considerada carne branca é um atrativo } \\
\text { para a compra. }\end{array}$ & 3,59 & 1,11 \\
$\begin{array}{l}\text { Promoções de preço para a carne de frango fariam com que eu a com- } \\
\text { prasse com mais frequência. }\end{array}$ & 3,42 & 1,35 \\
$\begin{array}{l}\text { O preço de a carne de frango é justo se comparado à sua saudabilidade. } \\
\text { De modo geral, considero que as embalagens de carne de frango são } \\
\text { adequadas. }\end{array}$ & 3,41 & 0,99 \\
$\begin{array}{l}\text { Pagaria mais pela carne de frango com embalagens que apresentassem } \\
\text { mais informações. }\end{array}$ & 3,30 & 0,97 \\
$\begin{array}{l}\text { O preço da carne de frango tem relação direta com seu benefício à } \\
\text { saúde. }\end{array}$ & 3,27 & 1,14 \\
$\begin{array}{l}\text { Acho justo pagar mais por uma carne de frango com data de fabricação } \\
\text { mais recente. }\end{array}$ & 3,05 & 1,36 \\
$\begin{array}{l}\text { Pagaria mais por uma carne de frango que apresentasse maior prazo de } \\
\text { validade. }\end{array}$ & 2,54 & 1,20 \\
$\begin{array}{l}\text { A carne de frango é muito cara. } \\
\text { Fonte: os autores. }\end{array}$ & 1,05 \\
\hline
\end{tabular}

Na Tabela 2, observa-se uma média geral de 3,28, com um DP médio de 1,13. O destaque dessa dimensão está na concordância em gostar da carne de frango, com média de 4,05, e em um nível inferior a 3 (ponto médio da escala) para a questão referente ao frango ser abatido em condições humanitárias, com o valor de 2,87 (leve discordância). Alguns respondentes revelaram não crer que os animais sejam abatidos sem algum tipo de sofrimento, fato aparentemente negativo à imagem do produto. Porém, no estudo de Reche, De Toni e Milan (2010), a questão de "pena" 
em relação ao abate dos animais não se configurou como pertencente à imagem central, posicionando-se na segunda periferia.

$\mathrm{Na}$ Tabela 3, referente à dimensão sensorial, a média geral das questões ficou em 3,23, com DP médio de 1,17. Destaque para a média obtida pela questão de comparação dos sabores das carnes de frango e bovina, que foi de 2,68. De forma geral, a carne de frango se apresenta superior à bovina e à suína. Moretti e Mendonça (2005) salientam que, no caso do produto cárneo, a percepção do consumidor é avaliada por meio dos atributos quantidade de gordura, saudabilidade, sabor e maciez.

Tabela 2 - Estatísticas descritivas da dimensão emocional

\begin{tabular}{lcc}
\hline \multicolumn{1}{c}{ Variáveis relativas à dimensão emocional } & Média & DP \\
\hline $\begin{array}{l}\text { Eu gosto de carne de frango. } \\
\begin{array}{l}\text { Pago um preço justo pela carne de frango em relação à satisfação geral } \\
\text { que ela me proporciona. }\end{array}\end{array}$ & $3,42,19$ & 0,98 \\
$\begin{array}{l}\text { Comprar uma marca conhecida de carne de frango me faz sentir bem } \\
\text { comigo mesmo. }\end{array}$ & 3,34 & 1,13 \\
$\begin{array}{l}\text { Sinto muito prazer ao consumir a carne de frango. } \\
\begin{array}{l}\text { A carne de frango é a mais adequada para refeições e encontros de famí- } \\
\text { lia e/ou com amigos. }\end{array}\end{array}$ & 3,13 & 1,21 \\
$\begin{array}{l}\text { O frango é abatido com o menor sofrimento possível, ou seja, em con- } \\
\text { dições humanitárias. }\end{array}$ & 2,87 & 1,09 \\
$\begin{array}{l}\text { Pagaria mais por uma carne de frango na qual o fornecedor informasse } \\
\text { garantias de abate sem sofrimento ao animal. }\end{array}$ & 2,86 & 1,24 \\
\hline $\begin{array}{l}\text { Fonte: os autores. } \\
\end{array}$
\end{tabular}

Tabela 3 - Estatísticas descritivas da dimensão sensorial

\begin{tabular}{lccc}
\hline \multicolumn{1}{c}{ Variáveis relativas à dimensão sensorial } & $\begin{array}{c}\text { Mé- } \\
\text { dia }\end{array}$ & DP \\
\hline A carne de frango é uma carne mais macia, se comparada à carne bovina. & 3,78 & 1,05 \\
A marca da carne de frango pode ser um diferencial no momento da & 3,65 & 1,13 \\
decisão de compra. & 3,56 & 1,12 \\
A carne de frango é uma carne mais macia, se comparada à carne suína. & 3,26 & 1,10 \\
A aparência da carne de frango é melhor que a da carne suína. & 3,11 & 1,27 \\
A carne de frango possui melhor sabor que a carne suína. & 2,96 & 1,18 \\
A aparência da carne de frango é melhor que a da carne bovina. & 2,86 & 1,22 \\
O odor da carne de frango é desagradável. & 2,68 & 1,26 \\
A carne de frango possui melhor sabor que a carne bovina. & &
\end{tabular}


$\mathrm{Na}$ Tabela 4, referente à dimensão racional/funcional, a média geral das questões resultou em torno de 3,6, com DP em 1,0. Destaque para a versatilidade da carne de frango, com média de 4,08, bem como para a questão com média de 2,85, referente à associação de altos preços da carne de frango com a sua qualidade. Nesse último caso, pode-se afirmar que o consumidor está valorizando outros atributos quando pensa na qualidade geral do produto, além de associá-la simplesmente ao preço como sinônimo de qualidade. Isso reforça o que Monroe (1990) afirma: o consumidor tende a incluir no seu julgamento outras informações e atributos como um indicador de valor nas suas intenções de compra, o que pode caracterizar uma predisposição para um esforço maior de pesquisa antes do ato da compra. Nesse sentido, aspectos como a familiaridade com o produto podem interferir no seu julgamento.

Também despertam atenção as médias das questões referentes à presença de hormônios na carne de frango (3,84 e 3,70). Nesse contexto, Bolis (2002) argumenta que essa crença vem de uma necessidade de as pessoas explicarem o rápido crescimento das aves. Porém, segundo esse autor, deveria haver uma conscientização dos consumidores de que o crescimento é fruto de melhoramento genético e dos avanços em nutrição animal, sanidade e manejo dos plantéis, além disso, deveria haver informação de que os hormônios não são permitidos pelas leis brasileiras e que amostras periódicas dos fabricantes são submetidas a avaliações laboratoriais. 
Tabela 4 - Estatísticas descritivas da dimensão racional/funcional

\begin{tabular}{|c|c|c|}
\hline Variáveis relativas à dimensão racional/funcional & Média & DP \\
\hline A carne de frango é versátil, oferecendo várias possibilidades de preparo. & 4,08 & 0,97 \\
\hline $\begin{array}{l}\text { A carne de frango é uma carne com menos gordura em relação a outras } \\
\text { carnes. }\end{array}$ & 3,90 & 1,05 \\
\hline A carne de frango é mais econômica que outros tipos de carne. & 3,86 & 0,96 \\
\hline A carne de frango contém hormônios em sua composição. & 3,84 & 1,18 \\
\hline A carne de frango possui níveis de colesterol menores que a carne suína. & 3,79 & 0,99 \\
\hline $\begin{array}{l}\text { O preço da carne de frango é justo em relação aos tipos de pratos que } \\
\text { posso preparar com ela. }\end{array}$ & 3,78 & 0,90 \\
\hline $\begin{array}{l}\text { A carne de frango é recomendável para dietas que visam à qualidade de } \\
\text { vida e ao bem-estar. }\end{array}$ & 3,78 & 1,03 \\
\hline $\begin{array}{l}\text { Considero que a carne de frango apresenta, de forma geral, um bom } \\
\text { nível de qualidade. }\end{array}$ & 3,72 & 0,79 \\
\hline A carne de frango possui menos calorias que os demais tipos de carne. & 3,72 & 0,95 \\
\hline $\begin{array}{l}\text { Pagaria mais por uma carne de frango que apresentasse, visualmente, } \\
\text { menos gordura. }\end{array}$ & 3,71 & 1,13 \\
\hline $\begin{array}{l}\text { Estou disposto a pagar mais pela carne de frango se tiver garantias de que } \\
\text { não contém hormônios. }\end{array}$ & 3,70 & 1,25 \\
\hline $\begin{array}{l}\text { Eu não espero nenhum tipo de problemas em relação ao consumo de } \\
\text { carne de frango. }\end{array}$ & 3,63 & 1,05 \\
\hline A carne de frango possui níveis de colesterol menores que a carne bovina. & 3,61 & 1,03 \\
\hline $\begin{array}{l}\text { Procuro me informar sobre os preços da carne de frango antes de com- } \\
\text { prar. }\end{array}$ & 3,19 & 1,31 \\
\hline $\begin{array}{l}\text { Geralmente conheço os preços da carne de frango praticados pelos prin- } \\
\text { cipais fornecedores. }\end{array}$ & 2,97 & 1,24 \\
\hline $\begin{array}{l}\text { De modo geral, quanto maior o preço da carne de frango, maior a sua } \\
\text { qualidade. }\end{array}$ & 2,85 & 1,14 \\
\hline
\end{tabular}

Quanto à dimensão simbólica de imagem (Tabela 5), a média geral das respostas ficou em 3,16 (DP médio de 1,12). A menor média foi a obtida pela questão sobre o significado especial da carne de frango para os respondentes, pois esta apresentou um valor de 2,60, não revelando, de modo geral, significado especial para pesquisados. Em contrapartida, salienta-se o valor obtido pelo fato de o produto ser considerado uma carne leve. 
Tabela 5 - Estatísticas descritivas da dimensão simbólica

\begin{tabular}{lcc}
\hline \multicolumn{1}{c}{ Variáveis relativas à dimensão simbólica } & Média & DP \\
\hline $\begin{array}{l}\text { Acredito que a carne de frango traga mais benefícios por ser uma carne } \\
\text { mais leve. }\end{array}$ & 3,57 & 1,11 \\
$\begin{array}{l}\text { O preço da carne de frango é justo por se tratar de um alimento que } \\
\text { contribui para uma alimentação equilibrada. }\end{array}$ & 3,34 & 0,99 \\
$\begin{array}{l}\text { Adquiro a carne de frango como alternativa em relação aos outros tipos } \\
\text { de carne, considerando sua qualidade. }\end{array}$ & 3,29 & 1,09 \\
$\begin{array}{l}\text { Se eu consumir carne de frango, acredito que esteja com uma alimenta- } \\
\text { ção equilibrada. }\end{array}$ & 3,27 & 1,10 \\
$\begin{array}{l}\text { Adquiro a carne de frango como alternativa em relação aos outros tipos } \\
\text { de carne, considerando seu preço. }\end{array}$ & 3,21 & 1,13 \\
$\begin{array}{l}\text { Estou disposto a pagar mais pela carne de frango pelo fato de ser uma } \\
\text { carne mais leve. }\end{array}$ & 2,84 & 1,15 \\
$\begin{array}{l}\text { A carne de frango tem um significado especial para mim. } \\
\text { Fonte: os autores. }\end{array}$ & 2,60 & 1,30 \\
\hline
\end{tabular}

$\mathrm{Na}$ Tabela 6, referente à dimensão visionária, desperta atenção a média obtida pela questão referente à procedência da carne de frango $(4,22)$. Essa resposta vem ao encontro do levantado no estudo de Reche, De Toni e Milan (2010), na medida em que os respondentes realmente gostariam de saber mais, em um futuro próximo, sobre a origem da carne.

Tabela 6 - Estatísticas descritivas da dimensão visionária

\begin{tabular}{lrc}
\hline \multicolumn{1}{c}{ Variáveis relativas à dimensão visionária } & Média & DP \\
\hline $\begin{array}{l}\text { Saber a procedência da carne de frango é importante. } \\
\begin{array}{l}\text { Marcas de fabricantes conhecidos de carne de frango representam um } \\
\text { produto mais seguro para o meu consumo. }\end{array}\end{array}$ & 3,75 & 1,12 \\
$\begin{array}{l}\text { Marcas de carne de frango as quais não estou acostumado significam } \\
\text { dúvidas em relação à qualidade. }\end{array}$ & 3,59 & 1,11 \\
$\begin{array}{l}\text { Tenho disposição para pagar mais por marcas de carne de frango produ- } \\
\text { zidas por fabricantes conhecidos. }\end{array}$ & 3,32 & 1,19 \\
$\begin{array}{l}\text { Acho justo que as marcas mais conhecidas cobrem mais pela carne de } \\
\text { frango. }\end{array}$ & 2,77 & 1,32 \\
\hline $\begin{array}{l}\text { Fonte: os autores. } \\
\end{array}$ & &
\end{tabular}

A Tabela 7, a seguir, apresenta os resultados referentes à percepção de valor e intenção de compra, com uma média geral de respostas em torno de 3,18 e desvio padrão médio de 1,11. Observa-se a média da questão apontada com o valor 2,77, que não associa uma oferta nos preços a uma qualidade inferior do produto, assim 
como observado em questão referente à dimensão racional/funcional. Revela-se, também, um grande equilíbrio entre as médias das respostas no que se refere à percepção de valor e intenção de compra.

Tabela 7 - Estatísticas descritivas da dimensão percepção de valor e intenção de compra

\begin{tabular}{|c|c|c|}
\hline $\begin{array}{l}\text { Variáveis relativas à dimensão percepção de valor e à intenção de } \\
\text { compra }\end{array}$ & Média & DP \\
\hline \multicolumn{3}{|l|}{ Percepção de valor } \\
\hline Em relação à qualidade geral da carne de frango, o preço é justo. & 3,42 & 0,95 \\
\hline $\begin{array}{l}\text { Se estou um pouco inseguro quanto à qualidade da carne de frango con- } \\
\text { sidero a opinião de amigos e/ou familiares para decidir sobre a compra. }\end{array}$ & 3,22 & 1,17 \\
\hline $\begin{array}{l}\text { A carne de frango me traz muitos benefícios em relação ao que gasto } \\
\text { para comprá-la. }\end{array}$ & 3,19 & 1,03 \\
\hline É fácil avaliar se o preço da carne de frango é justo. & 3,06 & 1,06 \\
\hline $\begin{array}{l}\text { Estou disposto a fazer um esforço adicional para encontrar preços mais } \\
\text { baixos ao comprar carne de frango. }\end{array}$ & 3,05 & 1,14 \\
\hline $\begin{array}{l}\text { Se percebo uma oferta nos preços da carne de frango acredito que o } \\
\text { produto apresente qualidade inferior. }\end{array}$ & 2,77 & 1,11 \\
\hline $\begin{array}{l}\text { O dinheiro que economizo para encontrar preços mais baixos de carne } \\
\text { de frango geralmente vale o meu esforço de tempo. }\end{array}$ & 2,76 & 1,12 \\
\hline \multicolumn{3}{|l|}{ Intenção de compra } \\
\hline $\begin{array}{l}\text { Recomendaria o consumo de carne de frango para meus amigos e } \\
\text { familiares. }\end{array}$ & 3,67 & 1,21 \\
\hline Devo comprar carne de frango o mais frequentemente possível. & 3,37 & 1,08 \\
\hline Devo consumir carne de frango o mais frequentemente possível. & 3,30 & 1,27 \\
\hline
\end{tabular}

\subsection{RESULTADOS DA ANÁLISE FATORIAL EXPLORATÓRIA}

Visando identificar relações entre as variáveis propostas pelo questionário (exceto as relacionadas à intenção de compra), bem como representar o conjunto original de variáveis por meio de um número de fatores intrínsecos, realizou-se a análise fatorial. Primeiramente, realizou-se o Teste de Esfericidade de Bartlett e o $K M O$, neste, foi encontrado um valor de 0,785 e no teste de Esfericidade de Bartlett, 0,0001, em níveis dentro do recomendado na literatura (HAIR JUNIOR et al., 2005). As comunalidades das variáveis ficaram acima de 0,5 , apresentando resultados satisfatórios, de acordo com os autores. 
Quando da primeira análise dos dados por meio da variância acumulativa, foram agrupados 20 fatores, com explicação de $69,1 \%$. A partir disso, foram sendo retiradas, sucessivamente, as variáveis com cargas menores do que 0,50 , conforme Hair Junior et al. (2005) e Kline (2011). Optou-se pela rotação Varimax dos fatores, como recomendado por Fávero (2009).

Depois de realizada a última rotação, obteve-se um total de 24 variáveis restantes. Foram extraídos oito fatores principais, com uma variância total explicada de $66,809 \%$ (Tabela 8). As variáveis da dimensão visionária restaram eliminadas em razão das suas baixas cargas. Apresentam-se, também, os Alfas de Cronbach $(\alpha)$ para cada fator, em níveis adequados para escalas exploratórias: superior a 0,6 , conforme Malhotra (2006).

Tabela 8 - Fatores resultantes e variáveis componentes

(continua)

\begin{tabular}{|c|c|c|}
\hline Fatores & Variáveis componentes & Cargas \\
\hline \multirow{3}{*}{$\begin{array}{l}\text { F1: } \\
\alpha=0,84\end{array}$} & $\begin{array}{l}\text { A carne de frango possui níveis de colesterol menores que a carne } \\
\text { suína. }\end{array}$ & 0,879 \\
\hline & $\begin{array}{l}\text { A carne de frango possui níveis de colesterol menores que a carne } \\
\text { bovina. }\end{array}$ & 0,836 \\
\hline & $\begin{array}{l}\text { A carne de frango possui menos calorias que os demais tipos de } \\
\text { carne. }\end{array}$ & 0,823 \\
\hline \multirow{4}{*}{$\begin{array}{l}\text { F2: } \\
\alpha=0,75\end{array}$} & $\begin{array}{l}\text { Adquiro a carne de frango como alternativa em relação aos outros } \\
\text { tipos de carne, considerando o seu preço. }\end{array}$ & 0,769 \\
\hline & $\begin{array}{l}\text { Adquiro a carne de frango como alternativa em relação aos outros } \\
\text { tipos de carne, considerando a sua qualidade. }\end{array}$ & 0,682 \\
\hline & $\begin{array}{l}\text { A carne de frango me traz muitos benefícios em relação ao que } \\
\text { gasto para comprá-la. }\end{array}$ & 0,602 \\
\hline & $\begin{array}{l}\text { O preço da carne de frango é justo por se tratar de um alimento } \\
\text { que contribui para uma alimentação equilibrada. }\end{array}$ & 0,515 \\
\hline \multirow{3}{*}{$\begin{array}{l}\text { F3: } \\
\alpha=0,75\end{array}$} & $\begin{array}{l}\text { Procuro me informar sobre os preços da carne de frango antes de } \\
\text { comprar. }\end{array}$ & 0,843 \\
\hline & $\begin{array}{l}\text { Geralmente conheço os preços da carne de frango praticados pelos } \\
\text { principais fornecedores. }\end{array}$ & 0,809 \\
\hline & $\begin{array}{l}\text { Estou disposto a fazer um esforço adicional para encontrar preços } \\
\text { mais baixos ao comprar carne de frango. }\end{array}$ & 0,727 \\
\hline
\end{tabular}




\begin{tabular}{|c|c|c|}
\hline Fatores & Variáveis componentes & Cargas \\
\hline \multirow{3}{*}{$\begin{array}{l}\text { F4: } \\
\alpha=\mathbf{0 , 6 9}\end{array}$} & $\begin{array}{l}\text { Pagaria mais por uma carne de frango que apresentasse maior prazo } \\
\text { de validade. }\end{array}$ & 0,805 \\
\hline & $\begin{array}{l}\text { Acho justo pagar mais por uma carne de frango com data de fabri- } \\
\text { cação mais recente. }\end{array}$ & 0,790 \\
\hline & $\begin{array}{l}\text { Pagaria mais por uma carne de frango que apresentasse, visualmen- } \\
\text { te, menor quantidade de água e/ou gelo. }\end{array}$ & 0,686 \\
\hline \multirow{3}{*}{$\begin{array}{l}\text { F5: } \\
\alpha=0,61\end{array}$} & $\begin{array}{l}\text { O preço da carne de frango é justo se comparado à sua saudabili- } \\
\text { dade. }\end{array}$ & 0,802 \\
\hline & $\begin{array}{l}\text { De modo geral, considero que as embalagens de carne de frango } \\
\text { são adequadas. }\end{array}$ & 0,693 \\
\hline & Em relação à qualidade geral da carne de frango, o preço é justo. & 0,609 \\
\hline \multirow{3}{*}{$\begin{array}{l}\text { F6: } \\
\alpha=0,65\end{array}$} & A carne de frango tem um significado especial para mim. & 0,690 \\
\hline & Eu gosto de carne de frango. & 0,630 \\
\hline & A carne de frango possui melhor sabor que a carne suína. & 0,625 \\
\hline \multirow{3}{*}{$\begin{array}{l}\text { F7: } \\
\alpha=\mathbf{0 , 6 1}\end{array}$} & $\begin{array}{l}\text { Estou disposto a pagar mais pela carne de frango se tiver garantias } \\
\text { de que não contém hormônios. }\end{array}$ & 0,803 \\
\hline & A carne de frango contém hormônios em sua composição. & 0,704 \\
\hline & $\begin{array}{l}\text { Pagaria mais por uma carne de frango que apresentasse, visualmen- } \\
\text { te, menos gordura. }\end{array}$ & 0,586 \\
\hline \multirow{2}{*}{$\begin{array}{l}\text { F8: } \\
\alpha=0,67\end{array}$} & $\begin{array}{l}\text { A carne de frango é uma carne mais macia, se comparada à carne } \\
\text { suína. }\end{array}$ & 0,858 \\
\hline & $\begin{array}{l}\text { A carne de frango é uma carne mais macia, se comparada à carne } \\
\text { bovina. }\end{array}$ & 0,798 \\
\hline
\end{tabular}

Observa-se que o Fator 1 englobou predominantemente variáveis da dimensão racional. Cabe ressaltar que o consumidor parece estar bastante interessado nas propriedades nutricionais da carne de frango, o que se justifica pelas altas cargas obtidas. A respeito disso, Verbeke e Viaene (1999) e Kennedy et al. (2004) salientam que a carne de frango é percebida pelos consumidores como de "alto valor agregado" em termos de saúde, principalmente se comparada a outros tipos de carne.

Já no Fator 2, encontram-se variáveis predominantemente da dimensão simbólica, bem como uma variável representante da dimensão relacionada à percepção de valor. Nesse contexto, ressalta-se, segundo os resultados descritivos, que a carne de frango representa uma alternativa às outras carnes, considerando preço, qualidade e alimentação equilibrada.

No Fator 3 se agruparam as variáveis pertencentes à dimensão racional/ funcional e à dimensão de percepção de valor. Claramente, observa-se aqui a 
preocupação com o fator preço, evidenciada pelas altas cargas obtidas para as variáveis. Nesse sentido, Monroe (1990) afirma que existem muitas situações nas quais somente o preço é a informação disponível sobre um produto (caso este comumente esteja presente na carne de frango) e, dessa forma, a percepção da qualidade do produto se forma a partir do preço indicado. Isso faz com que os consumidores tendam a preferir produtos com alto preço quando buscam qualidade, principalmente se existe a crença de que a qualidade das marcas disponíveis difere significativamente ou quando as diferenças de preço são muito grandes. Porém, o próprio autor coloca que o consumidor tende a incluir no seu julgamento outras informações e atributos como um indicador de valor nas suas intenções de compra.

A composição do Fator 4 é de variáveis essencialmente provenientes da dimensão físico-material. Notadamente, nesse Fator emergem aspectos da fabricação do produto, como a preferência por uma carne fresca, com maior prazo de validade e com aparentemente menos água/gelo. Cowan et al. (1999) salientam que os consumidores, de forma geral, não estão habilitados a realizarem análises mais profundas sobre a qualidade da carne de frango no ato da compra. Todavia, segundo os autores, a aparência parece ser o primeiro fator a ser observado em termos de qualidade em suas pesquisas com consumidores europeus, por exemplo.

No Fator 5 aparecem variáveis das dimensões físico-material e de percepção de valor, com destaque para a questão da "saudabilidade", evidenciada por Reche, De Toni e Milan (2010), bem como a embalagem do produto. Nesse sentido, Crutchfield, Kuchler e Variyan (2001) afirmam que, de forma geral, órgãos fiscalizadores da saúde, como o USDA, têm estimulado a escolha por produtos cárneos que apresentem na sua rotulagem informações claras e precisas a respeito de propriedades benéficas à saúde, enfatizando a economia anual gerada por essas informações aos cofres públicos, em termos de gastos com tratamentos de doenças derivadas do consumo de carne.

O Fator 6 resultou composto por variáveis das dimensões simbólica, emocional e sensorial. Porém, ressalta-se aqui a questão do atributo sabor, presente em duas questões dessa dimensão. Tal fato vem ao encontro da valorização atribuída pelo consumidor ao sabor do produto, identificada por Reche, De Toni e Milan (2010).

Na composição do Fator 7 predominam variáveis referentes à dimensão racional/funcional. Porém, salienta-se aqui a presença da disposição dos consumidores em pagar mais por uma carne que garantisse a ausência de hormônios e sua preocupação com esse atributo. Em relação a esse fato, Aguiar (2006) relata 
que, em pesquisas realizadas com consumidores de carne de frango, $78 \%$ dos respondentes acreditavam que a carne de frango recebia hormônios, alertando o quanto os consumidores são desinformados sobre isso.

Por fim, no Fator 8, encontram-se variáveis essencialmente sensoriais (29 e 28), ressaltando o atributo maciez, comparado a outros tipos de carne. Moretti e Mendonça (2005) afirmam que a percepção e a comparação dos diversos atributos do alimento são fatores determinantes no processo de tomada de decisão de compra e consumo de um produto em detrimento de outro. Os autores ainda salientam que, no caso do produto cárneo, a percepção do consumidor é avaliada por meio dos atributos quantidade de gordura, saudabilidade, sabor e maciez. Ressalta-se, também, que esse atributo também é constante da primeira periferia da imagem do produto, determinada na pesquisa de Reche, De Toni e Milan (2010).

De modo geral, poder-se-ia reclassificar (redistribuir) essas variáveis nos fatores obtidos, inclusive renomeando-os conforme indicado por Hair JUNIOR. et al. (2005) e Field (2013). Para esses autores, as variáveis com cargas maiores influenciam mais a seleção de nome ou rótulo para representar um fator. Assim, segue uma nova configuração de dimensões de imagem, com base na análise fatorial: F1 - Funcional; F2 - Simbólica; F3 - Racional; F4 - Físico-material (Qualidade do produto); F5 - Físico-material (Saudabilidade); F6 - Sensorial (Sabor); F7 Simbólica (Crenças); F8 - Sensorial (Maciez).

\subsection{RESULTADOS DA REGRESSÃO LINEAR MÚLTIPLA}

Visando identificar as dimensões mais relevantes para a intenção de compra da carne de frango, realizou-se a regressão linear múltipla. Como variável dependente, foi utilizada a média das três questões referentes à intenção de compra (Tabela 7), como independentes, as médias de cada um dos oito fatores obtidos.

Após a inserção dos dados, a regressão apontou que o conjunto de variáveis independentes (oito fatores ou dimensões) explica 50,5\% da variância da variável dependente (intenção de compra), a qual, segundo Malhotra (2001), refere-se à intensidade da associação entre as variáveis dependentes e a independente, ou seja, a proporção da variação total em Y (intenção de compra) decorrente da variação em X (variáveis independentes). Esse valor pode ser considerado satisfatório, se for considerado que existem outros fatores, além da imagem do produto, que podem 
influenciar na intenção de compra de um produto como a carne de frango e que não foram testados pelo modelo.

Observou-se que não houve problemas de multicolinearidade dos resíduos, já que a estatística de Durbin-Watson é aproximadamente igual a 2 (FIELD, 2013), e não houve valores VIF acima de 5 (FÁVERO, 2009). Além disso, a partir da significância obtida na Análise de Variância (Anova), de 0,000, é possível rejeitar a hipótese nula de não significância conjunta dos parâmetros da equação a 5\%, indicando que o modelo é significativo.

Partiu-se, assim, para a análise de significância estatística dos parâmetros de cada variável explicativa e do intercepto do modelo. Os resultados encontram-se na Tabela 9:

Tabela 9 - Resultados da Análise de Regressão

\begin{tabular}{|c|c|c|c|c|c|c|c|}
\hline \multirow{2}{*}{ Modelo } & \multicolumn{2}{|c|}{$\begin{array}{c}\text { Coeficientes não } \\
\text { normalizados }\end{array}$} & \multirow{2}{*}{$\begin{array}{c}\text { Coefi- } \\
\text { cientes } \\
\text { norma- } \\
\text { lizados } \\
\text { Beta }\end{array}$} & \multirow{2}{*}{$\mathbf{t}$} & \multirow{2}{*}{ Sig. } & \multicolumn{2}{|c|}{$\begin{array}{l}\text { Colinearidade } \\
\text { estatística }\end{array}$} \\
\hline & B & $\begin{array}{c}\text { Erro } \\
\text { padrão }\end{array}$ & & & & $\begin{array}{l}\text { Tole } \\
\text { rância }\end{array}$ & VIF \\
\hline Constante &,- 536 & ,388 & & $-1,383$ & ,168 & & \\
\hline F1 - Funcional & ,158 &, 072 & ,126 & 2,190 &, 030 & ,809 & 1,236 \\
\hline F2 - Simbólica & ,398 & ,084 & ,318 & 4,766 &, 000 & ,599 & 1,669 \\
\hline F3 - Racional &, 016 & ,057 & ,016 & ,290 & ,772 & ,859 & 1,164 \\
\hline $\begin{array}{l}\text { F4 - Físico } \\
\text { material (Qua- } \\
\text { lidade) }\end{array}$ &,- 065 & ,055 &,- 064 & $-1,174$ & ,242 & ,906 & 1,103 \\
\hline $\begin{array}{l}\text { F5 - Físico } \\
\text { material (Sau- } \\
\text { dabilidade) }\end{array}$ & ,247 & ,078 & ,180 & 3,183 & ,002 & ,829 & 1,206 \\
\hline $\begin{array}{l}\text { F6 - Sensorial } \\
\text { (Sabor) }\end{array}$ & ,343 & ,066 &, 330 & 5,212 &, 000 & ,664 & 1,505 \\
\hline $\begin{array}{l}\text { F7 -Simbólica } \\
\text { (Crenças) }\end{array}$ & ,035 & ,065 & ,030 & ,538 &, 591 & ,834 & 1,199 \\
\hline $\begin{array}{l}\text { F8 - Sensorial } \\
\text { (Maciez) }\end{array}$ & ,047 & ,059 &, 045 & ,806 & ,421 & ,862 & 1,160 \\
\hline
\end{tabular}

Fonte: os autores.

Obs.: a variável dependente: intenção de compra.

Na Tabela 9, observa-se que nem todas as dimensões explicativas possuem significância em $\mathrm{t}<$ 0,05. Inicialmente, os fatores (dimensões) F3, F4, F7 e F8 
apresentaram significância t $>0,05$ e, portanto, foram excluídos do modelo. Essas variáveis também foram aquelas que apresentaram os menores valores de tolerância, ou seja, seriam gerados altos valores de $\mathrm{R}^{2}$ se elaboradas regressões de cada uma delas com as demais dimensões explicativas.

Segundo Fávero (2009), o método de exclusão de variáveis refere-se ao procedimento backward, a partir do qual todas as variáveis são inicialmente incluídas no modelo e retiradas passo a passo em decorrência da análise da significância estatística t. Ao excluírem-se esses fatores (dimensões), o novo modelo apresentouse da seguinte forma:

Tabela 10 - Resultados da análise de regressão - Procedimento Backward

\begin{tabular}{|c|c|c|c|c|c|c|c|}
\hline \multirow{2}{*}{$\begin{array}{l}\text { Modelo } \\
\text { B }\end{array}$} & \multicolumn{2}{|c|}{$\begin{array}{c}\text { Coeficientes } \\
\text { não normaliza- } \\
\text { dos }\end{array}$} & \multirow[t]{2}{*}{$\begin{array}{l}\text { Coefi- } \\
\text { cientes } \\
\text { norma- } \\
\text { lizados }\end{array}$} & \multirow{2}{*}{$\mathbf{t}$} & \multirow{2}{*}{$\begin{array}{l}\text { Sig. } \\
\text { Tole } \\
\text { rân- } \\
\text { cia }\end{array}$} & \multicolumn{2}{|c|}{$\begin{array}{l}\text { Colinearida- } \\
\text { de estatística }\end{array}$} \\
\hline & $\begin{array}{l}\text { Erro } \\
\text { pa- } \\
\text { drão }\end{array}$ & Beta & & & & VIF & \\
\hline Constante &,- 446 & ,332 & & $-1,341$ & ,182 & & \\
\hline F1 - Funcional & ,158 & ,068 & , 126 & 2,321 & 021 & ,890 & 1,124 \\
\hline F2 - Simbólica & ,400 &, 080 & ,319 & 4,970 &, 000 & ,641 & 1,560 \\
\hline $\begin{array}{l}\text { F5 - Físico material } \\
\text { (Saudabilidade) }\end{array}$ & ,253 & ,077 & , 185 & 3,298 & ,001 & ,842 & 1,187 \\
\hline $\begin{array}{l}\text { F6 - Sensorial } \\
\text { (Sabor) }\end{array}$ & ,355 &, 063 & ,341 & 5,625 &, 000 & ,716 & 1,396 \\
\hline
\end{tabular}

Obs.: a variável dependente: intenção de compra.

Verificando-se a Tabela 10 (segundo o modelo), pode-se afirmar, então, que o modelo apresenta quatro dimensões com parâmetro de significância a 5\% e com VIF abaixo de 5,0, sendo elas especificamente as dimensões F6 (Sensorial/Sabor, beta de 0,34), F2 (Simbólica, beta de 0,32), F5 (Físico-material/Saudabilidade, beta de 0,19 ) e F1 (funcional, beta de 0,13 ), constituindo-se esses fatores ou dimensões como os mais significativos para a explicação da influência da imagem do produto para a intenção de compra dos consumidores. 


\section{CONSIDERAÇÕES FINAIS}

Na presente pesquisa, em continuidade ao estudo de Reche, De Toni e Milan (2010), teve-se como objetivo analisar e identificar as dimensões da imagem mais relevantes para a intenção de compra de carne de frango. Nesse sentido, evidenciaram-se as dimensões (fatores) Funcional, Simbólica, Físico-material (Saudabilidade) e Sensorial (Sabor). Desse modo, três entre as quatro dimensões são formadas essencialmente de atributos tangíveis e salientes.

De acordo com os atributos levantados, destaca-se que algumas características intangíveis são, de fato, parte do produto comprado. Atributos negativos e igualmente intangíveis também vão ao encontro do que afirma Lahlou (1995), para o qual os fatores "idealizados" podem ser determinantes para a rejeição ou aceitação de um alimento, independentemente de fatores organolépticos. Dessa forma, as representações sociais da alimentação e nutrição são características que fabricantes e distribuidores deveriam considerar nas suas estratégias de desenvolvimento e vendas.

Em relação a isso, conforme relatado por Mowen e Minor (2003), um consumidor que considera um maior número de dimensões sobre um produto é capaz de fazer distinções mais apuradas entre as marcas. Ademais, as dimensões identificadas como relevantes para a intenção de compra do produto se encontram disponíveis aos membros da cadeia avícola e profissionais de Marketing para a atuação direta em termos de ações com os mercados, visando a melhorias em vendas e consequentes aumentos em participações de mercado para as marcas que souberem explorá-las.

Em termos de limitações do presente estudo, pode-se afirmar que determinar a imagem de um produto representa uma atividade bastante complexa e subjetiva. Algumas variáveis podem ter sido influenciadas por tempo, incerteza, nível cultural, imparcialidade/parcialidade e crenças dos entrevistados.

Nesse caso, considera-se importante a continuidade de pesquisas sobre o tema. Como oportunidade, destaca-se a possibilidade de aplicar os instrumentos utilizados neste trabalho a um número maior de entrevistados e em locais diferentes (nos pontos de venda, por exemplo), ressaltando-se, também, alguns grupos específicos, como donas de casa e nutricionistas. 


\section{REFERÊNCIAS}

AGUIAR, A. P. S. Opinião do consumidor e qualidade da carne de frangos criados em diferentes sistemas de produção. 2006. Dissertação (Mestrado em Ciência e Tecnologia de Alimentos)-Escola Superior de Agricultura Luiz de Queiroz, Piracicaba, 2006.

ARENALES, M. C. Produção orgânica de aves de postura e corte. Agroecologia Hoje, n. 18, p. 11-13, 2003.

BARICH, H.; KOTLER, P. A framework for marketing image management. Sloan Management Review, v. 32, n. 2, p. 97-104, 1991.

BLACKWELL, R. D.; MINIARD, P. W.; ENGEL, J. Comportamento do consumidor. 9. ed. São Paulo: Cengage, 2005.

BOLIS, D. A. Análise de mercado para frangos orgânicos. 2002. Dissertação (Mestrado em Administração e Negócios)-Universidade do Oeste de Santa Catarina, Joaçaba, 2002.

COWAN, C. et al. Consumer perceptions of meat quality. Final report project Armis n. 4360. Dublin: Teagasc, 1999.

CRUTCHFIELD, S.; KUCHLER, F.; VARIYAN, J. N. The economic benefits of nutrition labeling: a case study for fresh meat and poultry products. Journal of Consumer Policy, v. 24, p. 185-207, 2001.

DE TONI, D. Administração da imagem de organizações, marcas e produtos. In: KUNSCH, M. M. M. K. (Org.). Comunicação organizacional: histórico, fundamentos e processos. São Paulo: Saraiva, 2009.

DE TONI, D. Administração da imagem de produtos: desenvolvendo um instrumento para a configuração da imagem de produto. 2005. Tese (Doutorado em Administração)-Universidade Federal do Rio Grande do Sul, Porto Alegre, 2005.

DE TONI, D.; MILAN, G. S.; SCHULER, M. As dimensões da imagem mercadológica. In: MILAN, G. S. (Org.). Administração mercadológica: teoria e pesquisas. Caxias do Sul: EDUCS, 2009. v. 3.

DE TONI, D.; SCHULER, M. Gestão da imagem: desenvolvendo um instrumento para a configuração da imagem de produto. RAC - Revista de Administração Contemporânea, v. 11, n. 4, p. 131-151, 2007. 
DICHTER, E. What's in an image. Journal of Consumer Marketing, v. 2, i. 1, p. 75-81, 1985.

FÁVERO, L. P. Análise de dados. Rio de Janeiro: Elsevier, 2009.

FIELD, A. Discovering statistics using IBM SPSS statistics. 4. ed. Thousand Oaks: Sage Publications, 2013.

FRANCISCO, D. C. A rastreabilidade segundo os atributos valorizados pelos consumidores: o caso da cadeia avícola do Rio Grande do Sul. 2004. Dissertação (Mestrado em Agronegócios)-Universidade Federal do Rio Grande do Sul, Porto Alegre, 2004.

GORDIN, M. H. O. Estudo das cadeias produtivas do MS: avicultura. Cuiabá: UFMS, 2002.

HAIR JUNIOR, J. F. et al. Análise multivariada de dados. 5. ed. Porto Alegre: Bookman, 2005.

HAWKINS, D. I.; MOTHERSBAUGH, D. L.; BEST, R. J. Comportamento do consumidor: construindo a estratégia de marketing. Rio de Janeiro: Elsevier, 2007.

HUBERT, A. Alimentation et santé: la science et l'imaginaire. Cahiers de Nutrition et de Diététique, v. 35, n. 5, p. 353-356, 2000.

KENNEDY, O. B. et al. Consumer perceptions of poultry meat: a qualitative analysis. Nutrition \& Food Science, v. 34, i. 3, p. 122-129, 2004.

KLINE, R. B. Principles and practice of structural equation modeling. 3 . ed. New York: The Guilford Press, 2011.

KOTLER, P.; KELLER, K. L. Administração de marketing. 14. ed. São Paulo: Pearson, 2012.

LAHLOU, S. Les représentations sociales de l'alimentation. Thèse de Psychologie Sociale pour le Doctorat nouveau régime. Paris: Ecole des Hautes Etudes en Sciences Sociales, 1995.

LEDOUX, J. E. O cérebro emocional. 2. ed. Rio de Janeiro: Objetiva, 1998.

LEVY, S. J. Interpreting consumer mythology: a structural approach to consumer behavior. Journal of Marketing, v. 45, i. 3, p. 49-61, 1981. 
LINDQUIST, J. D. Meaning of image: a survey of empirical and hypothetical evidence. Journal of Retailing, v. 50, i. 4, p. 29-38, 1975.

MALHOTRA, N. Pesquisa de marketing. 4. ed. Porto Alegre: Bookman, 2006.

MARTINEAU, P. The personality of the retail store. Harvard Business Review, v. 36, i. 1, p. 47-55, 1958.

MONROE, K. B. Pricing: making profitable decisions. 2nd. ed. New York: McGraw-Hill, 1990.

MORETTI, L.; MENDONÇA, P. S. M. Fatores que influenciam o consumo de carne de frango: saúde e preço. In: CONGRESSO DA SOCIEDADE BRASILEIRA DE ECONOMIA E SOCIOLOGIA RURAL, 43., 2005, Ribeirão Preto. Anais... Ribeirão Preto: SBESR, 2005.

MOWEN, J. C.; MINOR, M. S. Comportamento do consumidor. São Paulo: Pearson Prentice Hall, 2003.

PINTO, M. R.; LARA, J. E. A pesquisa na área de comportamento do consumidor: uma análise da produção acadêmica brasileira entre 1997 e 2006 . In: ENANPAD, 31., 2007, Rio de Janeiro. Anais... Rio de Janeiro: ANPAD, 2007.

RECHE, R. A.; DE TONI, D.; MILAN, G. S. Configuração da imagem de produto: o caso da carne de frango. In: EMA - Encontro de Marketing, 4., 2010. Anais... Florianópolis: ANPAD, 2010.

SCHIFFMAN, L. G; KANUK, L. L. Comportamento do consumidor. 6. ed. Rio de Janeiro: LTC, 2000.

SCHULER, M.; DE TONI, D.; MILAN, G. S. As dimensões da imagem mercadológica. In: MILAN, G. S. (Org.). Administração mercadológica: teoria e pesquisas. Caxias do Sul: EDUCS, 2009. v. 3.

SHETH, J. N.; MITTAL, B.; NEWMAN, B. I. Comportamento do cliente: indo além do comportamento do consumidor. São Paulo: Atlas, 2001.

SILVA, L. F.; FABRINI FILHO, L. C. Complexo avícola e questões sobre hábito alimentar. Caderno de Debate UNICAMP, v. 2, p. 41-61, 1994.

SILVA, L. F.; FABRINI FILHO, L. C. Complexo avícola e questões sobre hábito alimentar. In: SOLOMON, M. R. O comportamento do consumidor. 5. ed. Porto Alegre: Bookman, 2002. 
SPERS, E. E. Segurança do alimento. In: ZYLBERSTAJN, D.; SEARE, R. F. Gestão da qualidade no agribusiness: estudos e casos. São Paulo: Atlas, 2003.

STERN, B.; ZINKHAN, G. M.; JAJU, A. Marketing images: construct definition, measurement issue, and theory development. Marketing Theory, v. 1, i. 2, p. 201-224, 2001.

\section{UNIÃO BRASILEIRA DE AVICULTURA. Relatório anual da União}

Brasileira de Avicultura. Disponível em: < http://www.ubabef.com.br/ publicacoes>. Acesso em: 21 mar. 2015.

UNITED STATES DEPARTMENT OF AGRICULTURE/ECONOMIC SERVICE RESEARCH. Changing consumer demands create opportunities for U.S. food system. Food Review, v. 25, i. 1, p. 19-22, 2002.

UNITED STATES DEPARTMENT OF AGRICULTURE/ECONOMIC SERVICE RESEARCH. Livestock and Poultry: World Markets and Trade. Disponível em: <http://www.fas.usda.gov/data/livestock-and-poultry-worldmarkets-and-trade >. Acesso em: 21 mar. 2015.

VERBEKE, W.; VIAENE, J. Beliefs, attitude and behaviour towards fresh meat consumption in Belgium: empirical evidence from a consumer survey. Food Quality Preference, v. 10, p. 437-445, 1999.

ZALTMAN, G. Consumer researchers: take a hike! Journal of Consumer Research, v. 26, i. 4, p. 423-428, 2000.

\section{COMO CITAR ESTE ARTIGO:}

DE TONI, Deonir et al. Influência da imagem e percepção de valor na intenção de compra de carne de frango: um estudo quantitativo. RACE, Revista de Administração, Contabilidade e Economia, Joaçaba, Ed. Unoesc, v. 14, n. 3 , p. 1005-1034, set./dez. 2015. Disponível em: < http://editora.unoesc.edu.br/index. php/race >. Acesso em: dia/mês/ano.

De Toni, D., Reche, R. A., Larentis, F., \& Sperandio Milan, G. (2015). Influência da imagem e percepção de valor na intenção de compra de carne de frango: um estudo quantitativo. RACE, Revista de Administração, Contabilidade e Economia, 14 (3), 1005-1034. Recuperado em: dia/mês/ano, de http://editora.unoesc.edu.br/index. php/race 